\title{
The effect of ginger supplementation on IL2, TNF $\alpha$, and IL1 $\beta$ cytokines gene expression levels in patients with active rheumatoid arthritis: A randomized controlled trial
}

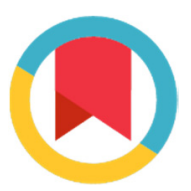

\author{
Naheed Aryaeian*1, Mahdi Mahmoudi*2, Farhad Shahram², Shiva Poursani², Fatemeh Jamshidi², Hajar Tavakoli ${ }^{3}$
}

Received: 5 Mar 2018

Published: 27 Dec 2019

\section{Abstract}

Background: Rheumatoid arthritis (RA) is a chronic autoimmune and inflammatory disease that affects the joints and consequently leads to the destruction of cartilage and bone lesions. Traditionally, ginger has been consumed in treatment of osteoarthritis, joint and muscle pain, neurological diseases, and inflammation of gums, tooth pain, asthma, stroke, diabetes, and constipation. The aim of this study was to determine the effect of ginger on some immunological and inflammatory markers in patients with rheumatoid arthritis.

Methods: In this study, which was performed during 2013-2016, 66 patients with active rheumatoid arthritis who referred to the rheumatology clinic at Shariati hospital were en-rolled. Patients were randomly divided into 2 groups: one group consumed 1.5 gr ginger per day, and the other group took roasted wheat flour (placebo), respectively. To determine the effect of confounding factors on the findings of the study, questionnaires for nutrient intake, physical activity, and medication were filled, and BMI was measured. For each participant, at the beginning and end of the study, Serum hs-CRP and mRNA levels of IL- $1 \beta$, IL- 2 and TNF- $\alpha$ were determined by ELISA and Quantitative Real Time PCR, respectively. Statistical analysis was performed using SPSS software. Significance level was set at $\mathrm{p}<0.05$.

Results: Results of the study showed ginger powder supplementation caused a significant decline in CRP ( $p=0.050)$ and IL- $1 \beta \mathrm{mRNA}$ level $(\mathrm{p}=0.021)$. TNF $\alpha$ mRNA levels reduced in ginger group compared to placebo groupalthough the difference was not significant between the 2 groups ( $\mathrm{p}=0.093$ ). Ginger had no effects on IL2 gene expression.

Conclusion: This study showed that ginger reduces inflammatory factors hs-CRP and IL-1 $\beta$ gene expression in patients with active RA and it seems that ginger can improve the inflam-mation in the patients.

Keywords: Ginger, Active rheumatoid arthritis, Inflammatory markers, Gene expression

Conflicts of Interest: None declared

Funding: Iran and Tehran Universities of Medical Sciences

\section{*This work has been published under CC BY-NC-SA 1.0 license. \\ Copyright $\subseteq$ Iran University of Medical Sciences}

Cite this article as: Aryaeian N, Mahmoudi M, Shahram F, Poursani Sh, Jamshidi F, Tavakoli H. The effect of ginger supplementation on IL2, TNF $\alpha$, and IL1 $\beta$ cytokines gene expression levels in patients with active rheumatoid arthritis: A randomized controlled trial. Med J Islam Repub Iran. 2019 (27 Dec);33:154. https://doi.org/10.47176/mjiri.33.154

\section{Introduction}

Rheumatoid arthritis (RA) is an autoimmune inflammatory disease that causes proliferation of synovial cells and leads to destructive lesion of joint cartilage and bone. The

Corresponding author: Dr Naheed Aryaeian, aryaeian.n@iums.ac.ir DrMahdi Mahmoudi, mahmoudim@tums.ac.ir

1. Research Center for Environmental Health Technology, Iran University of Medical Sciences and Department of Nutrition, School of Public Health, Iran University of Medical Sciences, Tehran, Iran

2. Rheumatology Research Center, Tehran University of Medical Sciences, Tehran, Iran

3. Departments of Cellular and Molecular Nutrition, School of Nutritional Sciences and Dietetics, Tehran University of Medical Sciences, Tehran, Iran disease is caused by both genetic and environmental factors, with a prevalence of approximately $1 \%$ of the worldwide population. In Iran, the prevalence of the disease is

\section{$\uparrow$ What is "already known" in this topic:}

There has been no sufficient evidence based on clinical trials to study the effect of ginger on patients with rheumatoid arthritis, osteoarthritis, and other muscular and joint pains.

In addition, to the best of our knowledge, no study has been conducted on the effect of ginger on IL1 $\beta$, IL2, and TNF $\alpha$ gene expression as inflammatory and immunityindexes in patients with RA.

\section{$\rightarrow$ What this article adds:}

This study found that ginger powder decreases CRP and IL-1 $\beta$ in patients with active rheumatoid arthritis and it seems that ginger can improve the inflammation in the RA patients by decreasing inflammatory factors. 
$0.33 \%$, which is lower than other parts of the world $(1,2)$.

The severity of illness and pain are closely associated with inflammation and oxidative stress (3-5). The antioxidant levels are lower in RA patients (6-7). An imbalance between Th1 and Th2 cells activity ratio increases Th17 cells activity and the level of cytokines mRNA secreted from Th0 or Th1 in peripheral blood; moreover, joint tissue is observed in patients who suffer from active rheumatoid arthritis (8-9). The increase in IL2 and IL2/IL4 ratio are good indicators of increased Th1/Th2 ratio (3). More than 40 antioxidants have been isolated from ginger rhizome. The major pharmacological activity of ginger is related to its phenolic active ingredients such as gingerols and shogaols (10). These compounds have antiemetic, fever, cough, inflammatory, diabetic, hyperlipidemic, and cancer nature (11). Ginger is known as a traditional treatment for relieving stiffness and pain in patients with osteoarthritis (10). Besides, ginger is safe and well-tolerated in doses up to 2 grams daily (12). However, there is insufficient evidence for the efficacy of this plant in the treatment of RA.

According to the National Institutes of health \& National Center for omplementary and Alternative Medicine (NCCAM), to date, there has been no sufficient evidence based on clinical trials to study the effect of ginger on osteoarthritis, rheumatoid arthritis, and other muscular and joint pains (13).

In addition, to the best of our knowledge, no study has been conducted on the effect of ginger on inflammatory and immunity factors gene expression in RA patients. Therefore, the present study was performed to study the effect of ginger powder on CRP level and proinflammatory cytokines in patients with active RA.

\section{Methods}

\section{Study design}

The present study was a double-blind randomized placebo controlled clinical trial that has been approved by medical ethics committee of Iran University of Medical Sciences, and written informed consent was obtained from all the participants. This study has been registered in the Iranian Center for Clinical Trials (No: 201207109472N4).

\section{Study population and intervention}

Participants were 66 (19-69 year-old) active RA patients with 2-year disease duration who were referred to a rheumatology clinic at Tehran Shariati hospital and fulfilled the American College of Rheumatology Criteria for RA during 2013-2016 (14). The exclusion criteria were as follow: history of hyperlipidemia myocardial infarction abnormal renal and/or hepatic function; taking vitamins and/or mineral supplements less than 2 months before the study; taking thyroid hormones, antihypertensive drugs, diuretics, and $\beta$ blockers alcohol contraceptives smoking pregnancy lactation; and changing medications (antimalaria and steroidal anti-inflammatory drugs).

Data on dietary habits, dietary supplements, smoking, and drug history were attained by interviewing. The participants were asked not to change their usual diet, physical activity, and prescribed medications during the study.
The patients were randomly divided (simple randomization) into 2 groups to receive either ginger or placebo capsules. Ginger was prescribed $1500 \mathrm{mg}$ daily as 2 capsules (each containing $750 \mathrm{mg}$ of ginger powder) by the researcher, and placebo contained wheat flour. Ginger and placebo capsules were produced in similar shape, size, smell, and color (wheat was roasted and then kept inside the ginger pockets for 2 weeks). The boxes of capsules have been coded by a statistician, and neither the researcher nor the patients were aware of the contents of the capsules (Placebo or Ginger). Moreover, the laboratory personnel were blind to the name and group of participants. Also, hsCRP, and IL- $1 \beta$, TNF $\alpha$, and IL 2 mRNA level were the primary outcomes.

Considering the results (mean $\pm \mathrm{SD}$ ) for CRP in the clinical trial led by Atashak (15), with a confidence level of $95 \%$ and power of $80 \%$, the sample size for each treatment group was calculated to be 26 patients.

Serum hs-CRP was determined using ELISA (Monobind, USA). Disease activity scores (DAS) were calculated based on erythrocytese dimentation rate and serum hs-CRP (17).

The intervention period was 12 weeks. Neither the researchers nor the patients were aware whether the patients belonged to the ginger or the placebo group. The patients were under treatment with disease modifying antirheumatic drugs (DMARDs: methotrexate, hydroxychloroquine, and prednisolone $<10 \mathrm{mg} /$ day) and did not receive anti-inflammatory drugs (NSAIDs) as far as possible. Compliance was estimated by intake of more than $90 \%$ of the supplements throughout the study in the 2 groups. Also, $7 \mathrm{cc}$ of blood samples were taken from the patients who met the inclusion criteria. To measure the serum level, the collected blood samples were sent to the research center's rheumatology laboratory.

\section{PBMC isolation and RNA extraction}

PBMCs were isolated from whole blood samples using Ficoll-Hypaque gradient (Sigma, 690PB-100A). Total cellular RNA was extracted from PBMCs using High Pure RNA Isolation Kit (Roche, Germany, 11828665001), according to the manufacturer's protocol. The quantity and quality of RNA was evaluated by spectrophotometer (NanoDrop ND-2000C, Thermo Fisher Scientific, USA).

\section{CDNA synthesis and $q P C R$}

Isolated RNA was utilized to make cDNA using Transcriptor First Strand cDNA Synthesis Kit (Roche, Germany, 04897030001). Real Q Plus 2x Master Mix Green (Ampliqon, 5000830) and Step One Plus Applied Biosystems Real Time PCR instrument (Foster City, CA, USA) were used for quantitative PCR. Primers are explained in Table 1. $\beta 2 \mathrm{M}$, a housekeeping gene, was used for normalization. Triplicate experiments were performed for each sample and the average $\mathrm{Ct}$ value was determined. Comparative $\mathrm{Ct}$ method was used for the analysis of IL-1 $\beta$, IL-2, and TNF- $\alpha$ gene expressions (16). Relative mRNA expression for each sample was computed using the following equation: relative mRNA expression $=(2(\mathrm{Ct} \beta 2 \mathrm{M}-\mathrm{Ct}$ of $\mathrm{cy}-$ tokines) $) \times 1000$. PCR Primers are shown in Table 1 . 


\begin{tabular}{|c|c|c|c|}
\hline Gene & Type & Sequence & Gene ID \\
\hline$I L-1 \beta$ & $\begin{array}{l}\text { Forward } \\
\text { Reverse }\end{array}$ & $\begin{array}{l}5^{\prime} \text { - atggcttattacagtggcaatgag }-3^{\prime} \\
\text { 5'- gtagtggtggtcggagattcg }-3,\end{array}$ & 3553 \\
\hline$I L-2$ & $\begin{array}{l}\text { Forward } \\
\text { Reverse }\end{array}$ & $\begin{array}{l}5,- \text { aactcetgtcttgcattgcac }-3, \\
5 \text { ' - gctccagttgtagctgtgttt }-3 \text {, }\end{array}$ & 3558 \\
\hline$T N F-\alpha$ & $\begin{array}{l}\text { Forward } \\
\text { Reverse }\end{array}$ & $\begin{array}{l}\text { 5'- cctgccecaatccctttatt }-3 \text {, } \\
5 \text { '- ccctaagccccaattctct }-3 \text {, }\end{array}$ & 7124 \\
\hline$\beta 2 M$ & $\begin{array}{l}\text { Forward } \\
\text { Reverse }\end{array}$ & $\begin{array}{l}5^{\prime} \text { - cctgaattgctatgtgtctggg }-3^{\prime} \\
5^{\prime} \text { - tgatgctgcttacatgtctcga }-3,\end{array}$ & 567 \\
\hline
\end{tabular}

\section{Statistical analysis}

Statistical analysis was done using SPSS software version 18 (SPSS, Chicago, IL, USA). Kolmogorov-Smirnov test was used to determine data compliance with the normal distribution. Quantitative variables were compared between the 2 groups at baseline and at the end of the study using an independent $t$ test. Quantitative variables within each group were compared with paired t test, before and after treatment. Qualitative variables were analyzed with chi-squared tests. All values were reported based on mean \pm SE. $P$ value $<0.05$ was considered asstatistically significant.

\section{Results}

In this study, 720 patients were assessed for eligibility, and 66 active RA patients entered the study. Patients were excluded from the study due to incomplete capsules intake and changing their medication ( 2 participants in ginger and 6 in placebo group). Of the 66 patients with active RA who entered the study, 58 completed the study (Fig. 1). Baseline characteristics of the participants are presented in Table 1. Both groups were similar regarding sex, age, and duration of RA in diagnosis, weight, body mass index (BMI), andenergy intake (Table 2). There were no significant changes in patients' physical activity, dietary intake, or medications during the study period. There was no significant difference

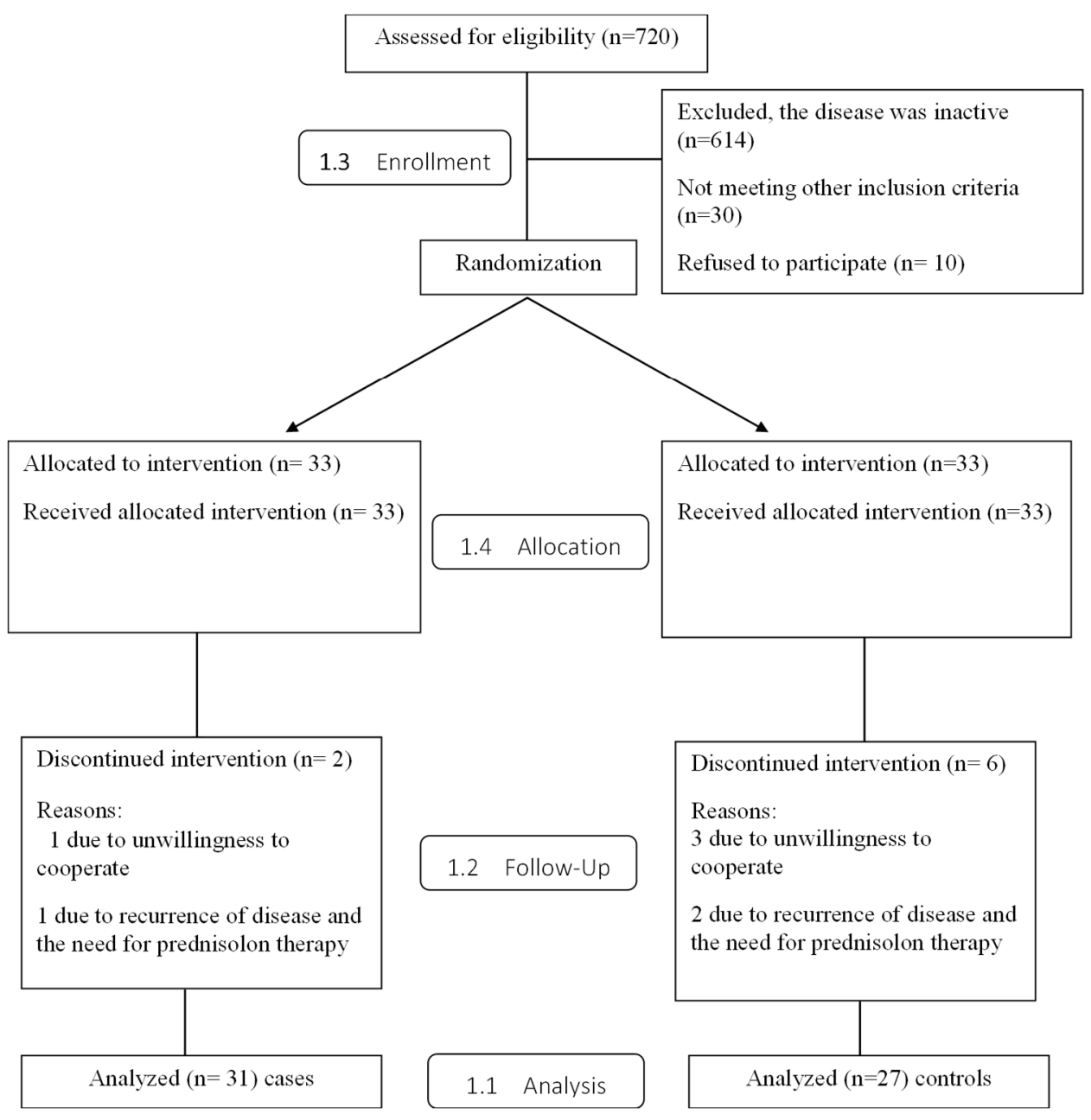

Fig. 1. Study setting and patients' allocation diagram 


\begin{tabular}{|c|c|c|c|}
\hline Variable & $\begin{array}{c}\text { Ginger group } \\
N=31\end{array}$ & $\begin{array}{c}\text { Placebo group } \\
N=27\end{array}$ & $\mathrm{p}$ \\
\hline Male/Female & $4 / 27$ & $3 / 24$ & $0.401^{\gamma}$ \\
\hline Age (years) $\dagger$ & $48.63 \pm 2.38$ & $46.67 \pm 1.94$ & $0.770^{*}$ \\
\hline Disease duration (years) $\dagger$ & $18.12 \pm 4.13$ & $14.87 \pm 4.13$ & $0.573^{*}$ \\
\hline Energy & $352 \pm 1517.3$ & $287 \pm 1537.7$ & 0.844 \\
\hline Weight $(\mathrm{kg}) \dagger$ & $73.45 \pm 2.13$ & $74.49 \pm 2.03$ & $0.620^{*}$ \\
\hline $\operatorname{BMI}\left(\mathrm{kg} / \mathrm{m}^{1}\right) \dagger$ & $29.23 \pm 0.83$ & $29.59 \pm 1.12$ & $0.790^{*}$ \\
\hline Corticosteroids (mg/d) & $8.10 \pm 0.7$ & $8.48 \pm 0.65$ & 0.881 \\
\hline Methotrexate $(\%) \gamma$ & $32(91)$ & 29(96) & 0.382 \\
\hline $\mathrm{ESR}^{3 \dagger}$ & $30.09 \pm 5.37$ & $25.59 \pm 4.22$ & 0.963 \\
\hline $\mathrm{DAS} 28^{4} \uparrow$ & $4.73 \pm 0.27$ & $4.51 \pm 0.27$ & 0.571 \\
\hline $\mathrm{hsCRP} \mathrm{evel}^{5} \dagger$ & $13.50 \pm 3.45$ & $13.01 \pm 2.25$ & 0.390 \\
\hline
\end{tabular}

$\dagger$ Data are presented as mean \pm SE.

$\mathrm{P} *$ Independent $\mathrm{t}$-test

$\mathrm{P}^{\gamma}$ Chi-squared test

$P$ value $<0.05$ is significant.

There were no significant differences between groups by T-test (for means) or Chi-square (for sex ratio).1-body mass index; 2- Equivalent dose of Prednisolone 3- Erythrocyte Sedimentation Rate 4-Disease Activity Score 28; 5-C-Reactive Protein

Table 3. hs-CRP level in ginger and placebo groups before and after intervention

\begin{tabular}{lcccc}
\hline Variables & & Ginger group & Placebo group & $\mathrm{p}^{\psi}$ \\
& & $\mathrm{N}=31$ & $\mathrm{~N}=27$ & \\
\hline hsCRP $(\mathrm{mg} / \mathrm{dL})$ & Before & $13.50 \pm 6.7$ & $13.01 \pm 8.4$ & 0.044 \\
& After & $7.62 \pm 5.1$ & $16.39 \pm 9.6$ & \\
& $\mathrm{p}^{*}$ & 0.05 & 0.38 & \\
\hline
\end{tabular}

$\mathrm{P}^{*}$ within group comparison (Paired t-test)

$\mathrm{P}^{\psi}$ between groups comparison (independent $t$ test of mean differences)

$P$ value $<0.05$ is significant.

between the 2 groups in the use of DMARDs and corticosteroids before and during the study intervention $(\mathrm{p}>0.05)$.

Table 3 demonstrates the mean and standard error of IL$1 \beta$, IL- 2 , TNF- $\alpha$, and hs-CRP. There was a significant reduction in CRP $(p=0.050)$ and IL-1 $\beta(p=0.021)$. In ginger group, TNF- $\alpha$ levels were reduced compared to placebo although the difference was not significant between the 2 groups ( $p=0.093$ ). Ginger had no effect on IL2 (Fig. 2).
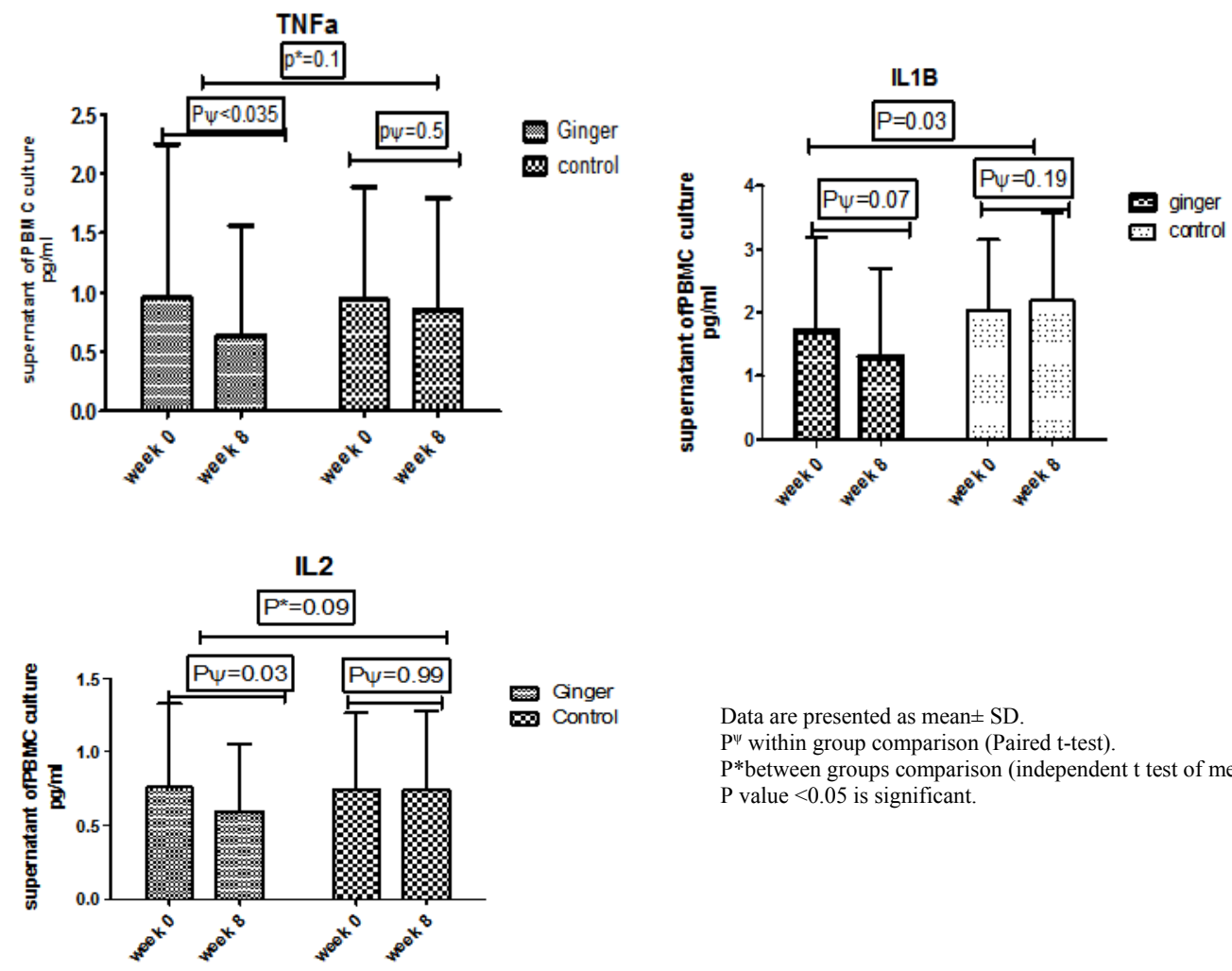

Data are presented as mean \pm SD.

$\mathrm{P}^{\psi}$ within group comparison (Paired t-test).

$\mathrm{P} *$ between groups comparison (independent $\mathrm{t}$ test of mean differences)

$P$ value $<0.05$ is significant.

Fig. 2. IL-1 $\beta$ IL-2 و TNF- $\alpha$ level in ginger and placebo groups before and after intervention 


\section{Discussion}

In the present study, 12-week supplementation with 1.5 gr/day ginger powder in active Rheumatoid arthritis patients caused significant reduction in IL-1B and hs-CRP. In addition, significant decrease was observed in TNF- $\alpha$ in ginger group.

To our knowledge, this was the first study on the effect of ginger on the cytokines related to inflammation in rheumatoid arthritis patients.

Some studies have shown that ginger decreases pain and inflammation in patients with osteoarthritis and muscle discomfort (18-20). Likewise, in traditional medicine, ginger intake is recommendedfor patients with arthritis muscle pain such as rheumatoid arthritis and osteoarthritis (20).

Some human and animal studies have displayed that antiinflammatory effect of ginger is due to decrease in proinflammatory cytokines and chemokines production. In a clinical trial on type 2 diabetic patients, supplementation with $1.600 \mathrm{gr} /$ day ginger powder for 12 weeks caused significant decline in serum PGE2 and CRP comparedto placebo; however, the decrease in serum TNF- $\alpha$ was not statistically significant between the 2 groups (10).

To our knowledge, very few studies examined the effect of ginger on $\mathrm{T}$ cells proliferation and function. Some in vitro studies found that ginger and its main gingerols can repress $\mathrm{T}$ cells proliferation and activation. In an in vitro study, volatile oil of ginger reduced the proliferation of $\mathrm{T}$ lymphocytes and total number of $\mathrm{T}$ helper cells $(\mathrm{p}<0.01)$. Also it incremented the percentage of T suppressor cells to total T lymphocytes $(\mathrm{p}<0.01)(21)$.

One study showed that ginger decreased the production of proinflammatory cytokines TNF- $\alpha$, IL-12, and IL- $1 \beta$, and proinflammatory chemokine MCP-1 and RANTES in vitro (22). In addition, ginger downregulated the expression of B71, B72, and MHC class II molecules. Moreover, a significant reduction in IFN- $\gamma$ and IL-2 productions by T cells in response to stimulation was observed (21). Also, ginger extract reduced macrophages activity as antigen presenting cell (APC) and inhibited T cells activity indirectly (23).

The decrease in the T-cells activity in the mentioned studies is not entirely consistent with the results of the present study that showed insignificant decrease in IL-2, which may be due to differences in ginger dose, sample size, and duration of the study; also, the present study was in vivo.

In Yasuka et al study, 6-Shogaol and 6-gingerol, the ingredients of ginger, inhibited TNF- $\alpha$ mediated downregulation of adiponectin expression via different mechanisms in 3T3-L1 adipocytes (24).

Moreover, in this study, there was a significant reduction in IL-1 $\beta(p=0.02)$. In Zhou et al study on the evaluation of ginger oil on rats and cell culture, similar to the present study, it was shown that this oil caused IL-1 $\beta$ secretion in peritonea's macrophages (21). In a study on rats with arthritis, red ginger ethanolic extract decreased inflammation by reducing PGE2 and nitric oxide production (25).

Several studies have shown the effect of ginger on inflammation improvement by decreasing of NF- $\kappa \mathrm{B}$ gene expression. Lee et al demonstrated that 6-gingerol isolated from Zingiber officinal exhibited anti-inflammatory effect by suppressing NF- $\mathrm{B}$ signaling pathways. Also, 6-gingerol significantly inhibited IkB phosphorylation and NF$\kappa \mathrm{B}$ nuclear activation (26). Recently, it has been reported that 1-dehydro-10-gingerdione is one of the significant compounds that has anti-inflammatory effect through inhibition of the NF- $\kappa \mathrm{B}$ regulated expression of inflammatory genes linked to TLR mediated innate immunity (27).

Expression of PPAR $\gamma$ in monocytes/MDMs (MonocyteDerived Macrophages) can be an indicator of disease activity and treatment efficacy in rheumatoid arthritis, because the patients with DAS-28 score $<3.2$ show the highest expression of PPAR- $\gamma$ (28). Some previous studies have shown that ginger components act as PPAR $\gamma$ agonists and can upregulate PPAR $\gamma$ target genes expression (29). Several studies have emphasized anti-inflammatory properties of PPAR $\gamma$ agonists in models of arthritis and different inflammatory cells. PPAR $\gamma$ agonists suppress translation of genes involved in joint pathology (such as TNF- $\alpha$, IL-1 $\beta$, gelatinase B, Matrix Metallo Proteinases (MMP) 9 and 13 (28). To date, potential anti-inflammatory characteristics of ligands of PPAR $-\gamma$ on the activity of rheumatoid arthritis in several arthritis experimental models have been observed (29). The strength of this study was that this research was the first clinical trial study on RA patients and its anti-inflammatory mechanism effect.

\section{Limitation}

The limitation of this study was the intake of anti-inflammatory medication by patients, which was controlled by omitting the patients who had changed the amount of prednisolone and antimalarial intake and by daily recording of the nonsteroidal anti-inflammatory drugs (NSAIDs) usage by patients.

\section{Conclusion}

In RA as anti-inflammatory disease, it seems that ginger may decrease inflammation by reducing some inflammatory markers production.

\section{Acknowledgments}

This survey was performed by grants from research deputy of Tehran University of Medical Sciences (Grant No: 22604) and Iran University of Medical Sciences (Grant No: 24361). We are thankful to the Research Institute for Islamic and Complementary Medicine for providing capsules in this study.

\section{Funding}

The study was funded by Iran and Tehran Universities of Medical Sciences. This study was conducted independently from the funders. The funders were not involved in study design, data collection, and analysis, and interpretation or in the writing of the report or its submission for publication.

\section{Ethical approval}

The study was approved by the respective research ethics committees and medicinal regulatory agencies (NO: IRCT 201207109472N4). Informed written consent was obtained from the patients before recruitment. 


\section{Transparency}

DP affirms that the manuscript is an honest, accurate, and transparent account of the study and that no important aspects of the study have been omitted and that any discrepancies from the study as planned have been explained.

\section{Data sharing}

No additional data available.

\section{Conflict of Interests}

The authors declare that they have no competing interests.

\section{References}

1. Gibofsky A. Overview of epidemiology, pathophysiology, and diagnosis of rheumatoid arthritis. Am J Manag Care. 2012;18(13 Suppl):S295302.

2. Davatchi F, Jamshidi AR, Banihashemi AT, Gholami J, Forouzanfar MH, Akhlaghi M, et al. WHO-ILAR COPCORD study (stage 1, urban study) in Iran. J Rheumatol. 2008;35(7):1384-90.

3. Aryaeian N, Djalali M, Shahram F, Djazayeri A, Eshragian MR. Effect of Conjugated Linoleic Acid, Vitamin E, Alone or Combined on Immunity and Inflammatory Parameters in Adults with Active Rheumatoid Arthritis: A Randomized Controlled Trial. Int J Prev Med. 2014;5(12):1567-77.

4. Aryaeian N, Shahram F, Djalali M, Eshragian MR, Djazayeri A, Sarrafnejad A, et al. Effect of conjugated linoleic acids, vitamin $\mathrm{E}$ and their combination on the clinical outcome of Iranian adults with active rheumatoid arthritis. Int J Rheum Dis. 2009;12:20-8.

5. Aryaeian N, Shahram F, Djalali M, Djazayeri A, Eshragian MR, Naderi $\mathrm{N}$, et al. The effect of conjugated linoleic acids, vitamin e and their combination on lipid peroxidation in active rheumatoid arthritis. Iran J Public Health. 2009;38:79-89.

6. Aryaeian N, Djalali M, Shahram F, Jazayeri Sh, Chamari M, Nazari S. Beta-Carotene, Vitamin E, MDA, Glutathione Reductase and Arylesterase Activity Levels in Patients with Active Rheumatoid Arthritis. Iran J Public Health. 2011;40(2):102-9.

7. Javadi F, Eghtesadi S, Ahmadzadeh A, Aryaeian N, Zabihiyeganeh M, Foroushani AR, et al.The effect of quercetin on plasma oxidative status, C-reactive protein and blood pressure in women with rheumatoid arthritis.J Int J Prev Med. 2014 Mar;5(3):293-301.

8.Feldmann M, Maini SR. Role of cytokines in rheumatoid arthritis: an education in pathophysiology and therapeutics. Immunol Rev. 2008; 223: 7-19.

9. Kawashima M, Miossec P. mRNA Quantification of T-bet, GATA-3, IFN-y, and IL-4 Shows a defective Th1 Immune Response in the Peripheral Blood from Rheumatoid Arthritis Patients: Link with Disease Activity. J Clin Immunol. 2005;25(3):209-14.

10. Arablou T, Aryaeian N, Valizadeh M, Sharifi F, Hosseini A, Djalali $M$. The effect of ginger consumption on glycemic status, lipid profile and some inflammatory markers in patients with type 2 diabetes mellitus. Int J Food Sci Nutr. 2014;65(4):515-20.

11. Manusirivithaya S, Sripramote M, Tangjitgamol S, Sheanakul C, Leelahakorn S, Thavaramara T. Antiemetic effect of ginger in gynecologic oncology patients receiving cisplatin. Int $\mathrm{J}$ Gynecol Cancer. 2004;14(6):1063-9.

12. Gregory PJ, Sperry M, Wilson AF. Dietary supplements for osteoarthritis. Am Fam Physician. 2008;77(2):177-84.

13. National Institutes of health \& National Center for complementary and Alternative Medicine (NCCAM) and FDA [cited 2012]; vailable from: https://nccam.nih.gov/health/ginger.

14. Neogi T, Aletaha D, Silman AJ, Naden RL, Felson DT, Aggarwal R, et al. The 2010 American College of Rheumatology/European League against Rheumatism classification criteria for rheumatoid arthritis: Phase 2 methodological report. Arthritis Rheum. 2010;62(9):2582-91.

15. Atashak S, Peeri M, Azarbayjani MA, Stannard SR, Haghighi MM. Obesity-related cardiovascular risk factors after long- term resistance training and ginger supplementation. J Sports Sci Med. 2011;10(4):685-91.

16. Schmittgen TD, Livak KJ. Analyzing real-time PCR data by the comparative C(T) method. Nat Protoc. 2008;3(6):1101-8.
17. Van Riel P, Fransen J. DAS28: a useful instrument to monitor infliximab treatment in patients with rheumatoid arthritis. Arthritis Res. Ther. 2005;7(5):189.

18. Srivastava K, Mustafa T. Ginger (Zingiber officinale) in rheumatism and musculoskeletal disorders. Med. Hypotheses. 1992;39(4):342-8.

19. Altman RD, Marcussen KC. Effects of a ginger extract on knee pain in patients with osteoarthritis. Arthritis Rheum. 2001;44(11):2531-8.

20. Haghighi M., Khalvat A, Toliat T, Jallaei S. Comparing the Effects of Ginger (Zingiber Officinale) Extract and Ibuprofen on Patients with Osteoarthritis. Arch Iran Med. 2005;8(4):267-71.

21. ZhouHua L, Yang-mei D, Qiang-min X. The modulatory effects of the volatile oil of ginger on the cellular immune response in vitro and in vivo in mice. $\mathrm{J}$ Ethnopharmacol. 2006;105(1-2):301-5.

22. Bernard M, Furlong SJ, Power Coombs MR, Hoskin DW. Differential Inhibition of T lymphocyte Proliferation and Cytokine Synthesis by [6]-Gingerol, [8]-Gingerol, and [10]-Gingerol. Phytother Res. 2015;29:1707-13.

23. Tripathi S, Bruch D, Kittur DS. Ginger extract inhibits LPS induced macrophage activation and function. BMC Complement Altern Med. 2007;8(1):1-7.

24. Isa Y, Miyakawa Y, Yanagisawa M, Goto T, Kang MS, Kawada T, et al. 6-Shogaol and 6-gingerol, the pungent of ginger, inhibit TNF- $\alpha$ mediated down regulation of adiponectin expression via different mechanisms in 3T3-L1 adipocytes. Biochem. Biophys. Res. Commun. 2008;373:429-34.

25. Shimoda H, Shan SJ, Tanaka J, Seki A, Seo JW, Kasajima N, et al. Anti-inflammatory properties of red ginger (Zingiber officinale var. Rubra) extract and suppression of nitric oxide production by its constituents. J Med Food. 2010;13(1156-62.

26. Lee TY, Lee KC, Chen SY, Chang HH. 6-Gingerol inhibits ROS and iNOS through the suppression of PKC- $\alpha$ and NF- $\kappa$ B pathways in lipopolysaccharide-stimulated mouse macrophages. Biochem. Biophys. Res. Commun 2009;382(1):134-9.

27. Lee HY, Park SH, Lee M, Kim HJ, Ryu SY, Kim ND, et al. 1-Dehydro-[10]-gingerdione from ginger inhibits IKK $\beta$ activity for NF- $\kappa \mathrm{B}$ activation and suppresses NF- $\kappa$ B-regulated expression of inflammatory genes. Br J Pharmacol. 2012;167(1):128-40.

28. Palma A, Sainaghi PP, Amoruso A, Fresu LG, Avanzi G, Pirisi M, et al. Peroxisome proliferator-activated receptor-gamma expression in monocytes/macrophages from rheumatoid arthritis patients: relation to disease activity and therapy efficacy, a pilot study. Rheumatology. 2012;51:1942-52.

29. Shahin D, Toraby EE, Abdel-Malek H, Boshra V, Elsamanoudy AZ, Shaheen D. Effect of peroxisome proliferator-activated receptor gamma agonist (pioglitazone) and methotrexate on disease activity in rheumatoid arthritis (experimental and clinical study). Clin Med Insights Arthritis Musculoskelet Disord. 2011;7(4):1-10. 